\title{
The TECHNOLIFE Project: An experimental approach to new ethical frameworks for emerging science and technology
}

Kjetil Rommetveit ${ }^{1}$, Kristrún Gunnarsdóttir ${ }^{2}$, Kim Sune Jepsen ${ }^{3}$, Margareta Bertilsson ${ }^{3}$, Fanny Verax ${ }^{4}$ and Roger Strand ${ }^{1}$

${ }^{1}$ Centre for the Study of the Sciences and the Humanities, University of Bergen, Norway

${ }^{2}$ CESAGen - Centre for Economic and Social Aspects of Genomics, Lancaster University, UK

${ }^{3}$ Department of Sociology, University of Copenhagen, Denmark

${ }^{4}$ REEDS Centre, Universit $\tilde{\complement} \odot$ de Versailles Saint-Quentin-en-Yvelines

Corresponding author: Kjetil Rommetveit <kjetil.rommetveit@svt.uib.no>

\begin{abstract}
This paper presents the development of an experimental methodology for empirical and participatory ethics of science and technology. It is designed to detect, understand and mediate public concerns. Science and technology evolve rapidly as a result of their internal dynamics as well as the optimization of subsidy for research and innovation in recent times. Ethical frameworks for governing these developments are confronted with considerable tensions in mediating the velocity of new innovations while securing more robust institutional guarantees in order to manage and regulate in time. We argue that existing frameworks need to evolve to become more sensitive to the diversity of technological and societal challenges, of envisioning futures, and of what counts as legitimate concerns. For this reason, we give socio-technical imaginaries a key role in developing an ethical framework. Our experimental approach is seeking to establish criteria for mediating a wide range of public opinion in ways that can become embedded in legitimate, institutional procedures. Our methodological approach is also seeking to mediate between lay ethics and the discourse of professional ethicists, recognizing the fragmented character of both. We draw on theoretical constructs in current STS research, notably, those dealing with complex relations between communities, real or imagined, and the rise of new publics whose voices can be distilled and heard through mediating channels. This experimental methodology forms the central component of an ongoing European Union FP7-funded project, TECHNOLIFE. ${ }^{1}$
\end{abstract}

Keywords: Communities, ELSA, emerging technologies, ethical frameworks, experimental methods, governance, imaginaries, publics, STS

\footnotetext{
${ }^{1}$ The TECHNOLIFE Project is funded by the European Commission, under FP7-SiS-2008-1 Ethics and new and emerging fields of science and technology . Grant agreement no. 230381.
} 


\section{Introduction}

This paper argues for the design of new empirical and participatory methodologies for detecting, understanding and mediating public attitudes and concerns in relation to new and emerging technologies. In particular, we argue for an evaluation of the imaginary as a performative constituent in deliberation and debate. Currently, ethics and governance are marked by certain "disappearance" of communication and intersubjective discourse which, in our view, presents us with a timely question about what we actually expect of regulatory practices, involving ethics, methods for increased public participation and technology assessment.

To explore this question further, we present in this paper the development of TECHNOLIFE, a project funded by the European Commission under the 7th framework program, Science-in-Society. The aim of TECHNOLIFE is to develop methodologies to engage with persons whose concerns are raised by rapid technological developments already affecting popular and occupational imaginations. The project focuses on three technological fields: biometrics and mobility, geo-visual applications, and body modification/enhancement technologies. We describe and reflect on the project's development to-date, while offering its design as a lens through which questions are raised about the conditions of accountability ${ }^{2}$, created by governing bodies and technologists in strategic planning and resource allocation to further technology innovations for the "public good".

In doing this, we situate TECHNOLIFE within a burgeoning body of research on science and technology governance, commonly referred to as Science and Technology Studies (STS). We also situate TECHNOLIFE within prominent studies of the Ethical, Legal and Socioeconomic Aspects (ELSA) of new and emerging technologies. The central concepts and theoretical preconditions, shaping the development of the project, draw on these domains of academic research, and we suggest some steps towards further developments.

Political, technical and social/cultural orientations and tendencies that enable innovations, also inform the ways in which our methodology is taking shape. Our claim is that many existing approaches for engaging with citizens are framed in too narrow terms within, mainly, expert-governed epistemologies which typically consider context, embodiment, emotions and

\footnotetext{
${ }^{2}$ We shall refer to "accountability" in a number of places in this text. The term has, during the latter 30 or so years, come to occupy a central position in attempts to establish practices and rules (such as ethical guidelines and legal obligations) aiming to improve relations of trust and responsibility throughout a number of institutions and businesses. However, the term evades exact definition and remains highly dependent on different meanings ascribed to it within different cultures and spheres of socio-technical organisation; see for instance Strathern 2000.
} 
imagination superfluous to the exercise of control and regulative expert reason. Although stated policy goals include the incorporation of ethical and related considerations in regulatory procedures, current measures tend to miss out on many central concerns about the potential and actual implications of new innovations (Expert Group on Science and Governance, 2007). They also tend to miss the emotive and motivational orientations in dialogue and envisioning of the future, both of which are fueled by the imaginations of those who are involved in such exercises. These "externalizations" of salient everyday reason and imagination, pertaining to the development and institutionalization of new technologies, account for unnecessarily risky and radically disruptive consequences in the face of environmental, social and technological challenges (Beck, 1992; Gibbons, 1999; Nowotny et al., 2001).

The development of TECHNOLIFE to-date can be summarized as follows. We have conducted a scoping (mapping) exercise which was carried out in relation to all three technology domains mentioned above. The aim was to identify "ethical issues of concern", but also to place these in relation to dominant trends in technology and policy development. A number of communities and publics have been identified which are, or are likely to be, affected by these technology developments. We are currently (August, 2010) in the process of inviting members of these communities to take part in an online deliberation exercise which will be carried out using the deliberation tool, KerDST ( http://kerdst.kerchantier.org/). A new version of KerDST (called KerTECHNO) has been developed specifically to capture imaginaries and imagined communities by creating an online forum where participants are encouraged to share experiences, express their attitudes and concerns, and discuss / debate the issues that are on their mind. Finally, as we look further ahead, the empirical and ethical analyses to follow are intended to draw together the mapping exercises, the results from these deliberations, and the academic literature on ethics and governance of science and emerging technologies.

TECHNOLIFE proposes a methodological approach through which affected and afflicted persons can participate in making technologies matter on their own terms, using their imaginative skills and capabilities. It is paramount to the aim of the project to establish an "experimental methodology" that takes into account the venue, the meeting ground, the agora of diverse kinds of knowledges and lifeworlds. But what does it mean to engage with persons at the level of the imagination? To begin to answer that question, we will describe the indications of emerging socio-technical formations, formulations and trends. We will expand on the concepts, community and public, both of which risk forestalling the conclusion of an 
investigation if they are too rigidly defined. Selecting participants for the deliberative forum deserves some attention in this respect, as we will discuss, and then we describe the media space designed for deliberations on state-of-the-art and the future of the technology domains this project focuses on. As we situate this approach within STS, ELSA and assessment frameworks more generally, we will round off with some reflections on the project's potentials and limitations.

\section{Conditions of possibility and conditions of accountability}

Scientific and technological advances have been given a prominent role in strategic planning for a safer, more innovative and competitive Europe in the 21 st century. As outlined in a recent communication by the European Commission, the member states are committed to sustainable development, aiming at a balanced economic growth, highly competitive "social market" economy, high employment, improved health care and social progress (European Commission, 2010). ICT-related developments are high on this agenda and so is the convergence of cutting-edge science and technologies, bringing together nanotechnology, biotechnology and bio-mimesis, cognitive science and a range of other specialties that interface with information and communication technologies (see European Commission, 2009a, 2009b; see also e.g. Bibel, 2004).

It is certainly not new that governing bodies liaise with academe and industry to push science and technology innovations in the name of common interests and shared societal values. The framework programs of the European Commission have been developed in close collaboration with research leaders and visionaries. For example, an advisory group was commissioned in 1999 for the Information Society Technologies (IST) priority of the $6^{\text {th }}$ framework program. The group advised the Commission to use a vision of ambient intelligence (AmI) to launch the IST program (e.g. Aarts and Encarnação, 2008). In other words, an AmI vision was positioned as an initiative, open to contributions from academic and industrial researchers to develop the "key-enabling" technologies. This vision quickly became operational in the sense that a strategic research agenda was carved out and a subsidiary budget distributed to European electronics research, materials science and engineering to the amount of $€ 3.7$ billion over four years.

We believe this example illuminates how potent imaginaries are in pushing technological innovation processes. It also illustrates how there is a corresponding lack of frameworks for invoking greater degrees of accountability and responsibility for socio-technical developments and their unintended side-effects at early stages of innovation and development. This is also a 
matter of democracy and the introduction of a wider set of imaginaries and visions into the socio-technical co-production of futures. For example, an important strategy in developing the AmI vision was scenario-building and analysis (ISTAG, 2001). These scenarios persuasively disclosed possible (and seemingly desirable) future lifeworlds, enabled by AmI applications. But these lifeworlds were dominated by technical thinking to urge a technological push, as research leaders later admitted (e.g. Aarts and Grotenhuis, 2009). Nonetheless, the ISTAG scenarios and the extensive promotion of this vision in the early 2000s helped to create conditions of possibility, as Heidegger would put it (Heidegger 1977). The future was disclosed in ways that seemingly could meet all sorts of societal and cultural challenges such as more efficient transport, more productivity, better social cohesion, health monitoring, safety and security, and easier access to information and entertainment in private, public and occupational settings. And, it was to those ends that the practical and economic means were brought into being, i.e., to push ahead and develop the necessary devices and infrastructures to enable this future.

If we consider the three technology domains TECHNOLIFE researchers are focusing on, we can see how their developments and deployments are also supported by persuasive scenario-building and visionary work which reveals the current lifeworld ${ }^{3}$ as well as future lifeworlds of radically reconfigured human-worlds, human-to-human and human-machine relationships. For example, biometrics are central to an emerging discourse of securitization and the assumption that we can adequately manage and control the mobility of people in and out of a stronger and safer Europe by using biometrics for identification, detection and discrimination into categories such as "trusted traveler", "threat to public order" or "illegal immigrant" (European Commission 2008). It is no secret either that industry in recent year has pushed for developments and further deployment of biometrics, and governing bodies have signed on (Hayes 2006; Joint Research Center 2005). Geo-visual and geo-information systems have disclosed the terrain as a "playground" for tracking and monitoring the movements and whereabouts of objects, persons and natural phenomena — of managing farmlands, residential developments, natural resources, law enforcement and disasters (National Research Council 2007). These technologies also reveal future terrains through predictive modeling, in terms of risk and security, and how to manage the futures made possible with such modeling. Body modification and enhancement technologies disclose a

\footnotetext{
3 "Lifeworld" is a much debated and theorised concept within philosophy and sociology, especially in parts oriented towards phenomenology and hermeneutics. Here we pragmatically define it as "the totality of practices, meanings and competences that constitute the general horizon of individuals' cognitive capacities". In somewhat more popularised terms it can also be understood as the general context of personal and communal life.
} 
future world of more capable, healthier and longer lasting bodies and minds, even supersoldiers and super-intelligence (see e.g. Roco and Bainbridge, 2002). One can argue that science fiction has for a long time played a major role in cultivating these visions, but so do recent developments in the use of implants, the use of "smart" prosthesis, and advances in reconstructive surgery-i.e., what these developments currently deliver, but also what they promise the future can look like. We will be discussing these technology domains in more detail below. Here we underscore the role of visionary work and projection in creating the necessary conditions to cultivate purpose and direction (or roadmaps) for science and technology innovations, and their capacities for mobilizing human, economic and technological resources for the sake of their realization.

There is less room today for national governments to directly participate in innovation and deployment processes, such as was the case with the Manhattan Project. International competition and globalization have changed the ways in which national policies and local industries can lay out directives and exert influence. Rather, as Fleischer et al put it, there is a "concentration of national governments on the shaping of framework conditions for innovation" (Fleischer et al, 2005, p.1113). The framework programs of the European Commission are a case in point where, also, guidelines are drawn on how to meet the societal challenges of the present as well as of envisioned futures. An aging population, projections on population growth, health service challenges, future financial markets, epidemics, climate change, and future security concerns, are prominent examples of such drivers. Dominant imaginaries and visions both establish a diagnosis of broader background of socio-technical and environmental challenges, as well as projecting the relevant means for action in dealing with them. As we stated above, scientific and technological advances are given a prominent role in preparing for and managing futures. So, we can see quite clearly how conditions of possibility are cultivated in the shaping of frameworks, distribution of money and the impression of an urge to be competitive at the cutting-edge of progress. We shall now look closer at the conditions for assessing current affairs and envisioned futures.

The very question of what counts as adequate assessment does not necessarily ask the question of how we can improve accountability. But it does address the question of how innovation processes and deployments are accountable. The current EU guidelines for creating an Innovation Union, set the focus on solving major and urgent societal challenges (European Commission, 2010). Innovations will have to answer the needs of society and ever since the 6th framework program took off, pan-European reflection and debate has been extensively encouraged on the relationship between science, technology, society and culture. 
To this end, the Commission has funded numerous projects which, among other things, have drawn attention to societal tensions and vastly diverse perceptions and perspectives on impact, legitimacy, intended and unintended consequences. The assessment frameworks have been both formal and informal, including impact and risk assessments, ethical and legal reviews, media analysis, foresight, studies of public perception and opinion, or the "classical" technology assessment (TA). For example, TA is a scientific calculative approach to costbenefit trade-offs and predictions of impact. The latest thinking on assessment, however, is increasingly considering non-calculative and non-economic aspects, such as social-cultural resources, environmental damage, health or, simply, quality of life. A growing number of disciplines and stakeholder groups are involved in considering these other aspects. One can argue then, that the European Commission has also created conditions for ever more complex evaluations which have broadened the scope of accountability as we have come to realize that science and technology innovations are also socio-cultural innovations.

In developing and expanding conditions of accountability, the European framework programs are openly acknowledging the political foundations of policy-making. Political aims and objectives, set to target the great societal challenges as they are stated in policy briefs and communications of the Commission, are echoed in calls for research bids which specifically target these same aims and objectives (see e.g. the latest FP7 calls published in July, 2010). But we see a number of interconnected issues which are difficult to resolve, and we mention three in particular. The first centers on the question of whether we should focus on the potential consequences of technologies which are already in the last stages of development and deployment, rather than concerning ourselves with the ways in which future lifeworlds are envisioned and planned for. Focusing on the former can address directly questions of accountability, responsibility and legitimacy in cases where non-intended, negative side effects occur. But the need for early deliberation and more democratic construction of future lifeworlds, has implications far beyond mere technical, precautionary measures. The second issue concerns the particular complications that arise in evaluating so-called "enabling" technologies. These are technological prerequisites for other technologies, products and services, but in and of themselves they hardly have an obvious direct connection with specific applications, e.g., nanotechnology or pattern recognition algorithms. The challenges are complex enough when looking at new configurations of systems, devices and services that we already know, more or less, how to put together. For example, assessing health care technologies may require traditional socio-economic analysis with cost-benefit trade-offs, which then are viewed in relation to broader social-cultural considerations and questions 
about the distribution of costs and benefits within larger systems. These broader evaluations have significant bearing on our understanding of how health care, social care, social cohesion (or lack thereof), housing, inequalities, etc., interface.

Perhaps the biggest challenge, however, are the limits of prediction in forecasting and roadmapping. Even when evaluation and public consultation measures are aimed at technologies in the last stages of development and deployment, forecasting or roadmapping is still on the table as part of the "evidence" that enables evaluation and consultation. The use of biometrics and GIS-related technologies are examples of that, e.g., the "roadmap" to a safer and more secure Europe or environmental forecasting. But if we were to aim at improving the conditions of accountability, we need to explore our culture of accountability (Strathern 2000) and culture of governance (Jasanoff 2005) and ask what the necessary conditions are for cultivating wider participation, interactive knowledge-making and humility in assessment and decision-making (see Jasanoff, 2003). Should we not ask for purpose and direction in order to be able to intercept and influence innovation in its development stages? How do we envisage lifeworlds with nanotechnology in 10+ years from now? Are we happy to subsidize research into pattern-recognition algorithms if we suspect that they will be used to identify our faces from a distance? Whose visions are these and to whom are these visions of future lifeworlds accountable?

Improving the conditions of accountability requires thinking about how better to democratize the future. What perhaps is most telling about the example of the AmI vision, is that it gradually dawned on visionaries and research leaders that the very lifeworlds projected in the ISTAG scenarios were simply not desirable. Apart from the fact that imagined AmI applications were unsafe and unacceptably intrusive, as demonstrated by FP7-funded ESLA research, SWAMI (Wright et al, 2008), these imagined support systems, devices and services were not very relevant, meaningful, helpful or even interesting - they were not what people want (Aarts and Grotenhuis, 2009). As the senior director of Trends and Strategy at Philips Design has elaborated, there is an urgent need to open the future to broader participation - to involve social and cultural innovators, the creative industries, and ordinary people, in cocreating the future (Green, 2007). Although this may seem like a genuine philanthropic gesture, it remains to be seen who is actually invited to co-create futures and who is left outnot to mention who pays for and benefits from "desirable" enhancements and reconfigurations of lifeworlds enabled by new and emerging technologies. But we can still take the brunt of the idea seriously, that there is an urgent need to open the future to broader democratic deliberation. It is precisely the objective of TECHNOLIFE to do this but, importantly, with 
the aim to help improve the conditions of accountability - to look for new ways to promote discussion and dialogue across cultural, administrative and occupational barriers, and explore the imagined communities and socio-technical imaginaries embedded in attitudes, hopes, fears and concerns, and uncertain future projections. We will now turn to insights gathered from STS and ELSA research in order to shed better light on the underpinnings of the TECHNOLIFE project.

\section{Criteria for accountability: insights gathered from STS and ELSA research.}

In this section, we discuss some of the insights gathered from STS and ELSA research, and how these insights inform the TECHNOLIFE project. In particular, we consider the work done in relation to risk, crises and critical decision-making, and the critiques that have emerged in relation to mediating institutions for public engagement, ethical reviews and technology assessments.

Throughout the last four decades or so, a number of mediating institutions have emerged at the interface of science, technology and society. Ethics boards and commissions, new assessment frameworks and public participation exercises are outstanding examples - all of which may be seen to begin to answer the call for increased accountability and corporate responsibility (see for instance O'Neill 2002; Strathern 2000). Such mediating institutions have taken into account the realization that ever more developments in science and technology, as they relate to medicine or the environment for example, are mixed blessings. Science and technology developments have actually been the strongest factors in creating the global "risk society". They can realistically be seen as the constituent parts of predominant problems as much as they are a part of solutions to problems we face (Beck and Bonss 2001; Beck 1992). Also, a number of recent crises in areas such as energy, the climate and the economy, call for decisive action in the face of risk. The call is for action on changing our societies, i.e., our established global patterns of living, consuming and producing. However, none of our novel institutions seem particularly capable of contributing adequately toward such goals.

Many of the policy problems can be addressed by reference to the issue of framing which is widely discussed in studies of how shared imaginaries of social and natural phenomena come to be defined and established on the basis of selective sets of values, interests and entrenched procedures. These studies, and the analyses they present, have contributed greatly to the understanding of policy problems, for example, in the governance of environmental issues as well as in bioethics and biomedicine (e.g. Jasanoff 2005). When joined with studies 
into the public understanding of science (e.g. Irwin and Wynne, 1996), such approaches are capable of casting considerable light on many contentious issues as well as the communication problems arising at the science/society interface. Concerning the tendencies towards greater participation in S \& T policy, some of the shortcomings of so-called public participation can be better understood by looking at presuppositions about rationality and agency that go into the construction of participants in such exercises, such as "the public", "the citizen", "the patient", and so on. They can also be better understood if we look at the institutions and practices that are charged with the task of engaging "publics" and assessing science and emerging technologies. We have identified three central components that act as significant barriers to improved participation, communication and deliberation, given the ways in which they are conceived of, practiced and configured. These are mediating institutions, knowledge-creation and the language of rights.

Institutions. Across a number of policy areas and issues of governance, the central tenet of mediating institutions lies in a promise to bring democracy and lay decision-making into fields previously reserved for experts. The stated aims are co-responsibility and wider distribution of accountability: clinical decision making (through autonomy and informed consent), environmental governance (through increased participation), technology assessment (providing and distributing knowledge about risks and consequences). In the process, however, these very same institutions have tended towards becoming new expert regimes (Expert Group on Science and Technology, 2007). The drive towards specialization, the "outsourcing" of domains of reality to experts, is deeply entrenched in Western societies (Beck and Bonss 2001; Latour 1993). It is little wonder then, that novel institutions, in establishing themselves, take on some of the same sectarian characteristics they were meant to counter and challenge. This indicates a need for such institutions to continuously renew themselves and to reconsider their mandate, and especially so if the stated motivation is one of improving democracy in decision-making on science and technology policies.

Knowledge. The forms of knowledge and practice that eventually dominate within mediating institutions relate to the point made in the previous paragraph, i.e. the institutional forms of expertise that have emerged. A central problem we see here is how the strong authority, enjoyed by the sciences and engineering, has encouraged the adaptation of some of their language and methods. One example is the application of social choice theory and other decision and economic theories based on specific notions of rational agency (see for instance Taylor 1985). If such views of human agency and rationality are upheld within mediating institutions, then experts are justified in formally framing facts and potential risks of a matter, 
to which lay persons and other publics can then contribute their opinions according to a set of predefined options. However, a number of studies into the public understanding of science contradict the view that people, if only provided with the right factual information, will also make the "right" decisions, or indeed any decision whatsoever. In most cases, the concerns of people relate more to their everyday lifeworlds, and less to problems as they are defined by scientists or engineers.

Rights. In many cases, inclusion and participation in technical decision-making will be formalized through a language of rights: that of the "autonomous individual" to be informed, or of the "public" to be included. In accordance with the two previous points, subjectivities such as the individual and the public tend to be framed as impartial and neutral observers of objective facts, rather than active, imaginative and knowledgeable agents with insights and memories (Jasanoff, 2003). One example concerns problems with using informed consent, originating in clinical face-to-face encounters, as a tool for policy in the implementation of large epidemiological databases and biobanks (Brekke and Sirnes 2006). Whereas the giving of information and the taking of consent may make a lot of sense, where the single individual and his or her health is concerned, this practice seems ill-fitted to deal with large-scale technological restructurings of health care systems (Rommetveit 2008). Serious problems can also be observed throughout a number of public consultation exercises, notably the UK's GM Nation, in which case the wide-spread mistrust and skepticism about genetically modified organisms was written off as the government decided not to take the advice of the public (Irwin 2006). This was one of the biggest public consultation exercises ever carried out by a government in the name of citizens' right to participate and have a say. But why carry out a public consultation if, in the end, the resulting popular opinion is not taken into consideration? One argument put forward by the British government was that the GM debate had been hijacked by a number of interest groups and ideologists, such as Greenpeace. An image of the non predisposed and objective "citizen" and "public" was put forward, the argument being that only those with no clear interest in the case could be relied upon for advice (ibid.). However, granted that we are facing serious problems with democratic participation and genuine interest in issues of governance (European Commission, 2001), how can it be that the dis-interested observer and decision-maker is called upon to remedy this state of affairs? Does dis-interestedness, neutrality and objectivity constitute unique rights to participation?

To come back to the argument we made in the previous section, our culture of accountability and culture of governance needs serious rethinking in order to improve the conditions of accountability. As we have now explored, we also need to (re)discover the 
criteria for accountability. If our institutions are poorly equipped because they cultivate particular forms of specialized knowledge which are inadequate in democratizing decisionmaking, then we do not have adequate criteria for accountability either. If dominant forms of knowledge and knowledge-making rest on inadequate conceptions of human agencies, then we do not have adequate criteria for engaging them either. If inclusion and participation in decision-making is mainly formalized through a language of rights, and those with interests and ideologies have no right to be heard and taken seriously, we do not have adequate criteria for democratic participation and decision-making.

It is with these considerations in mind that the TECHNOLIFE project set out to develop an experimental methodology which acknowledges local contexts, embodiment, emotions and people's imaginations as integral to the exercise of participation, of exerting influence and applying regulative reason. "Publics" or "communities", whoever they are, should have greater opportunities to participate in making technologies matter on their own terms, using their imaginative skills and capabilities. In the remaining sections we will describe our progress to-date and then come back to the main issues outlined in this and previous sections in reference to our learning so far.

\section{Our scoping exercise}

The scoping exercise was conducted by our partners whose scholarly commitments are STS and ELSA research into the use of biometrics (Sutrop 2010), the use of geographic information systems (Gadal, 2008), and future visions of body modification and enhancement (Holm, 2007). These exercises delivered elaborate descriptions of developmental traits and their potential impact on culture at large ${ }^{4}$. Also, by reviewing specifically the ethically contentious issues, known already to be of concern to European citizens and civil societies, the exercises expanded on ways in which the new technologies have captured popular and occupational imaginations.

For example, the scoping paper on "Biometrics and the European Border" underscores the drift in priorities set by the European Council between 1999 and 2009, i.e., between the Tampere program (1999), the Hague program (2004), and the Stockholm program (2009). Commitments to freedom, based on human rights, democratic institutions and the rule of law, shifted significantly with new strategies aiming to strengthen the area of freedom, security and justice in the European Union with a particularly strong emphasis on security measures (European Parliament, 1999; Council of the European Union, 2004; European Commission,

\footnotetext{
$4 \quad$ The scoping papers can be downloaded from www.technolife.no
} 
2004; Council of the European Union, 2009). A discourse of securitization (Bigo, 2006) has gradually taken hold in strategic planning and development of the shared visa system and border control for the Schengen region - the manifestation of that discourse nowhere as prominent as in the introduction of biometrics as a process towards strengthened freedom, security and justice.

Remarkably little has been done in the way of engaging publics and a range of occupations who are, one way or another, affected or afflicted by these developments. Simultaneously, securitization has become the dominant trope for promoting or opposing problems of immigration and border control-now and in the future - a discourse which is by no means unknown to publics at large. Security-led approaches depend on the metaphor of striking the right balance between security, freedom and justice, but they struggle to formulate agendas on how privacy and freedoms can be protected in concrete settings. Particular complications arise here against the reinforcement of security and the involvement of judicial and law enforcement authorities in aggregating and disseminating ever more personal information on both citizens and non-citizens of Europe. As the scoping paper suggests, striking the right balance "stretches deep into concrete processes and negotiations shaping institutions, legal frameworks and technologies". At the same time, it is subject to doubt to what degree the securitization discourse, with relating efforts to regulate through privacy and data protection regimes, really captures the many and complex interactions between citizens, states and the EU. Thus, concepts of trust, control, national and regional identities, visions of statehood, etc., should also be explored and introduced in public debates. This is one central example of how the TECHNOLIFE methodology may insert itself between official policy discourse and popular responses.

A scoping paper on the ethical dimensions of Geographic Information Systems foregrounds the expanding polymorphic nature of geographic, geo-referenced and spatial information. The use of GIS has rapidly migrated from mainly military uses to urban planning, resource management, epidemiological analysis, tracking of socio-economic fluctuations and, more recently, to serve as templates for citizens using imaging, tracking and modeling technologies at home or on their smart-phones. High resolution of remote-sensing imagery and the range of mapping tools now available are radically diversifying the representation of space. Place and belonging are concepts which need consideration as well as how the scale and resolution of information, participation, place, belonging and right to privacy, actually intersect. High resolution analysis of human activity, in particular, is 
associated with the potential monitoring of the movements of individuals for political control (e.g. National Research Council, 2007).

Open geo-data access for political institutions, professionals and civil society has been, and still remains, the central concern in relation to the development of these technologies. Simultaneously, the rapid development of Google Earth and related applications, and the increase in use of mobile nomad systems has not been given due attention. The latter operate real-time geo-localization and geo-traceability. (e.g. the 3G+ mobile system and the GRSS mobile network). As the scoping paper suggests, "[e]very part of the Earth, of the geographic space is today geo-visualizable. Every geographic object is geo-referenced and everybody on the Web or the $3 \mathrm{G}+$ can look [at] it". But not only can everybody now, in principle, look at it, modeling and tracking is being made available through commodification.

Finally, significant challenges arise with respect to our trust in maps, models and images, now that modes of producing, diffusing and using geo-referenced materials undergo rapid changes. Whereas previously the exclusive domain of one professional community (i.e. GIS), “open" applications such as Google Earth significantly expand the numbers and character of both producers and users. This happens at the same time as the applications in question are called upon to assist in the solving of increasingly complex problems where stakes are high, such as climate change and flood planning. How does trust in people, technologies and institutions keep up as we become seemingly ever-deeper entrenched in natural processes through rapidly emerging digital media?

A final scoping paper on "The Body" foregrounds body-enhancement in the science fiction literature as well as underscoring both signification and controversy surrounding "The Body" in the bioethical literature. Among the preliminary findings within this research line, we find, among other things, an increasing preoccupation with immortality, both within the ethics and the science fiction literature throughout the last 10-15 years. This development largely corresponds with the emergence of transhumanism within bioethics and as a global popular movement (e.g., Bostrom, 2005). We also observe, in novels such as the Neuromancer (Gibson, 1984), in academic analysis (Hayles, 1999), and in regulatory discourses (especially through data and privacy protection), a digital and technical re-casting of the old Cartesian dualism between mind and body. Today, old cultural and religious dividing lines are re-drawn as we increasingly come to occupy two realms: On the one hand there is the digital world, through online identities in gaming (Second Life, etc.) or large-scale databases used for governance of populations. On the other hand there is the "real" world of the embodied self, which also seems to enjoy its renaissance through proliferating "body 
cultures" (tattoos, fitness, fashion, cosmetic surgery, etc.), or novel biosocieties (Rose, 2007). The latter are organizing around specific diseases and emerging biomedical identities, many of which border on enhancement applications. The relationship between these two realms are by no means simple: We increasingly turn to the Internet for information in cases of "reallife" uncertainties, such as disease diagnosis. We observe, in a number of fields, imaginaries of overcoming imperfections, ailments, shortcomings and finitudes of the embodied self: people may turn to the body, making a fetish of new body cultures; they may, virtually speaking, leave the body behind for a new existence in cyberspace; they may also turn to techno-scientific utopias, as in Ray Kurzweil's notion of The Singularity, promising to overcome all dualisms through technology.

We see in these summaries from the scoping exercise, how new and emerging technologies are relevant to policy considerations and academic discourse, but importantly also to the lives of citizens. Far from being "complete" descriptions they nevertheless indicate how developmental traits capture and interact with both popular and occupational imaginations. New tools become commodities, new systems are installed to sort and manage crowds, and body modification and enhancement is either speculated on or actually tried and tested. However, what counts as ethically contentious issues or "hot" political issues is not necessarily all that clear. In order to even begin to approach such uncertainties, the TECHNOLIFE team decided that such issues need to be better identified in the first place, not only by those with privileged access to common concerns raised by the deployment of new technologies - policy makers, scientists, engineers, ethicists or activists - but also by those who, for one or another reason, are affected or afflicted in the capacity of their occupations or because they are in some other way socially sorted-immigrants, transhumanists, students, children, unemployed, criminals, sick, elderly, so on and so forth. To further develop this approach, the TECHNOLIFE team embraced the idea that issues of concern (Latour 2005) can serve as gravitational centers around which communities and publics (new or old) assemble and self-organize. Such assemblages would be indicative of emerging new sociotechnical formations, formulations and trends in ethically and politically significant ways. In particular, we searched for "hot topics" that already are shaping debates in public domains and concern the relevant technologies, i.e., in news media, popular literature and entertainment. In other words, the prerequisite here is that there is already a certain amount of debate / media attention to draw on which can serve as springboards for deliberations with invited participants. 


\section{What/who should count as a "community" or a "public"?}

Our point of departure is that publics organize around certain important issues of various and changing concerns to them. In turn, such concerns may not only depend on the nature of the issue at stake (and its family of potentially related issues), but also on the social or private backgrounds or communal affiliations of people entangled in different affairs. In this respect, a public cannot be reduced to a body, categorically concerned with one issue only-e.g., defending freedom of speech as its means and ends of self-assembling. Rather, a public is better conceived of as a continuous oscillation of entangled voices from hybrid communities, thus, being affected for different reasons. In short, TECHNOLIFE conceives of a public as a "polyphony" of the many attitudes and concerned voices of communities, both actual and potential. They form (or can form) in relation to emerging issues regarding new technologies of all kinds. In this lies the first imperative of our experimental methodology, another term for the idea of the self-creation of phantom publics (Dewey 1927).

This central idea of the TECHNOLIFE methodology, that issues (of many concerns) can serve as gravitational centers of self-assembling and continuously self-organizing hybrid publics, is in line with recent writings on the subject (Marres 2005). It takes an issue to spark publics into political motivation and concern. In this sense, a public never exists in the absence of specific attitudes, concerns and political motivations, brought into being by virtue of the different and diverse disputes that come to matter when people of different social backgrounds, and with different experiences of belonging together, are somehow suddenly confronted with an issue. In this sense, publics are also politically uncertain. They are experimental spaces of evolving deliberations (e.g. online forums, social networking, and the like), set apart from conventional communities, which often prescribe to people valuable and normative reasons for belonging with others. In this sense, a public is something very different from a community, a central distinction being the different notions of normativity, debate and guidelines for action.

A central presupposition of TECHNOLIFE is that there exist, "out there", several groups possessing valuable knowledge, and already engaged with socio-technical developments relating to the three technology domains. At the same time, the knowledge in question is of a more indefinable character than expert knowledge, and the engagement may be less explicit and directed than that of, say, a political organization. Thus, a central argument is that issues of concern, due to the previously remarked limitations (or absences) of mediating institutions, 
are not being articulated and brought into regulatory discourse. A number of ethical and political issues slip through the cracks of attempts to establish and promote accountability.

In our work so far, four main types of groups and/or categories have been considered:

1. “Classical” imagined communities (Anderson, 2006 [1983]), defined and constituted by shared imaginaries in time and space, and emerging through common media, technologies and administrative practices, typically within national boundaries.

2. Imagined communities qua "interest groups" who show an interest in/concern for/attention to technology X.

3. Groups or categories imagined by us the researchers, through our preliminary analysis, as groups or categories who may be affected or constructed through technology $\mathrm{X}$ and whose attitudes, concerns, narratives, and/or imaginaries, might be under- or misrepresented in the political or academic-ethical areas (as suspected by us).

4. Groups of people encountered at points of interception and interaction with technology $\mathrm{X}$, i.e., persons engaged at some stage of deployment and operation (concretely or imaginatively, directly or indirectly) in concrete settings.

For instance, in the case of Biometrics and the European border, "European citizens" might be a "classical" imagined community constituted by the "Schengen technology", including the biometric passport (group type 1). Privacy/human rights groups could be type 2, perhaps some groups of North-African immigrants would be type 3, while immigration officers and embassy staff would be type 4. The TECHNOLIFE approach is open to all of these groups or categories, and they can also be combined, say, if a particular interest group in the future wishes to apply the TECHNOLIFE approach to mobilize around certain attitudes or concerns.

Groups of type 4 merit a particular research interest and, as they might dominate in all three research lines, we shall explain in more detail what they present to us. By identifying "hot topics", centering on a particular technology, we can also identify heterogeneous assemblages of persons already concerned with these "hot topics" and related matters by, simply, engaging in the everyday operation and use of that same technology in the occupational or social function they fulfill. Hence, a central idea is that people who engage with technologies because of their ordinary occupations might also carry valuable experiences and knowledges which typically are not considered adequately in technology assessments or other types of mediating institutional practices. These voices provide insider accounts of how people imagine themselves tied up in technological issues with others as well as opening up 
the possibility to reflect on, what we call, the socio-epistemological backgrounds of such imaginaries.

This choice of participants reflects the importance of inquiring into the unquestioned political background of social, technological and occupational life. The voices of those partaking in the everyday shaping of an uncertain technological development through their social function would be able to reflect upon the importance of that function and potentially modify it. It is, therefore, theoretically possible to bring to the forefront of deliberation the different / similar concerns of participants as representative of imagined communities. In other words, the potential for people to become politically and ethically engaged with, what ought to be the issues of concern for communities living with a particular set of technologies, becomes one aspect of pursuing the consequences of those same technologies. Rather than simply accepting an occupational function, people will have the opportunity to justify their views and motivations, as well as their imaginations of a social life entangled in technological issues. Methodologically, the background motivations people might have, to associate in relation to technological issues of their own concern and imagination (and on their own epistemological terms) ought to be moved into the experimental foreground of deliberation. Indeed, we argue that real and "imagined" communities have the right to shape and orient the technological developments they are also affected by.

\section{Creating an "opening challenge" with short films}

For each of the three research lines a short film has been developed as a teaser or trigger for discussion and debate. Each film contains basic information about technological developments and their intersections with ethical or political issues. Playing on a number of genres, such as action films and science fiction, the films differ from documentary or promotional films, or from science communication films. Intentionally designed to transmit ambiguous messages, the aim is primarily to engage the viewer more on an emotional than an epistemic or "rational" level (a prerequisite for which is that the viewer is already somehow concerned by and entangled in the topic).

For instance, the film on Digital Globes starts out with a description of the traditional role of maps. It then briefly describes how, today, maps and globes are digitalized and moving online. Without further explicating its next move, the film then describes the role of maps and models in the management of future natural disasters, particularly focusing on flooding and risk management. The increasing reliance on online digital representations for management of the future may raise questions such as Who makes the maps? Can maps be trusted? and 
Whose interests are being served through predominant models, predictions and forecasts? By focusing on concrete homes, environments and people being hit by flooding, the film aims to introduce such questions through a primary identification: What if this happened to you? How would you see the future for yourself, your family and the community in which you live?

Along similar lines the Biometrics film describes the digitalization and securitization of public spaces and passage points for travelers. Biometrics is described as offering the potential of easier, faster and more secure travel, but also as providing the infrastructure for increased surveillance. Possible applications such as detection of suspicious behavior and tracking of individuals' movements are described in ways that do not separate sharply between fact and fiction. The main part of the film tells the story of one individual in a crowded street being singled out and identified as a "suspect" by a software program. Through database searches the movements of the person are tracked and mapped before he is finally identified as an EU citizen and acquitted as a "trusted individual". The film ends by focusing on African travelers trying to enter "Fortress Europe", and the question is raised again, whose interests are encoded in emerging technological infrastructures. Could biometrics be a help to asylum seekers by providing more secure identification, or will predominant nationalist and anti-globalist sentiments feed into technological border management at the European level?

The Body line film differs somewhat from the other two insofar as it takes place in an imagined medical research facility in the not-so-distant future. The film centers on a Nordiclooking medical doctor promising individualized, off-the-shelf enhancements and modifications for a number of major and minor ailments and "imperfections" of the human body. The film plays on issues of commodifying and technicalizing the body, alluding to distinctions between the normal and pathological, the ideal and the concrete, treatment and enhancement. It introduces examples from history and other cultures, such as the corset, bounded feet (China) and neck extensions among an African tribe. A major counter example is introduced through images of athlete bodies from the 1936 "Nazi Olympics". The dangers of the past are nevertheless discarded as irrelevant by the Nordic doctor: "For me, normality is a state of perfection".

The three films contain a number of references, messages, counter-messages, images, perspectives and associations aimed to produce both engagement (through provocation) as well as a state of estrangement and uncertainty. Due to their contradictory and incomplete structures, the contents of the films cannot be fully described in words but must be drawn on in different ways by each viewer. The films are accompanied by narration, but, whereas the 
narration is aiming for relative simplicity, the images are filled with ambiguity and a multiplicity of information and associations. The main aim here is to trigger discussions while at the same time avoiding a rigid framing of the issues at hand. Thus, any conflicting messages or complex hints are meant to counter simplistic framing of issues.

Upon entering the discussion forum, participants will be asked to reconstruct and give their opinion/reaction to the films, and this will form the starting point for the creation of visions and ensuing deliberations. So, how will these articulations of visions and deliberations take place?

\section{The road ahead: Deliberations in a virtual forum with KerDST}

As we have now described, the three films will be presented in a virtual forum, facilitating discussions and deliberation ${ }^{5}$. In this section we describe the main characteristics of this forum and its underlying software, the KerDST platform.

The original version of the KerDST (Deliberation Support Tool) is an on-line tool offering users a multi-stakeholder multi-criteria deliberation framework that can be applied to any desired situation of choice or discussion (for a description see O'Connor, Bureau and Reichel 2007). It includes the KerBabel Deliberation Matrix (DM) and the KerBabel Indicator Kiosk (KIK) (see http://kerdst.kerchantier.org/). The KerBabel Deliberation Matrix is foremost an ordering and representation tool. In its original form it is made up of three dimensions or axes: the scenarios axis, the issues axis, and the stakeholders axis. The result is a three-dimensional structure representing all "nodes" in a matrix where scenarios, issues and stakeholders have been listed, typically following face-to-face focus-group discussions with stakeholder representatives. In the actual "deliberation", participants give their vote on a set of issues (agree/disagree/neutral etc) in relation to a set of scenarios. Each participant can also leave comments to explain his or her vote. Once the voting is completed, a round of discussion can begin, in which everybody now has transparent, ready-to-hand access to the "opinions" of the people they are talking to on each debated issue, i.e., by means of the graphical color-coded representation on how their votes sit in the three-dimensional matrix.

For the purposes of TECHNOLIFE, a significant alteration has been made which is to say that a whole new module has been designed to facilitate textual online exchange of participants who are not co-present - a virtual focus-group or forum which precedes and aims to underpin formal KerBabel voting. In order to facilitate and encourage such a development, the overall deliberative exercise is divided into two distinct phases. The first is an open virtual

\footnotetext{
And as far as permitted by resources, also tried out in offline, face-to-face situations.
} 
forum of textual exchange aiming to elicit articulations of future scenarios and issues that should be debated. TECHNOLIFE aims at capturing narratives emanating from imagined communities whose members are asked to create, assess and discuss (in textual format) the scenarios presented in the films, each of which introduces a set of issues. As described in the previous section, these issues are broached by the films, but the role of the facilitator is essential in guiding the ensuing discussions and identifying or suggesting topics that may be relevant to explore further. For this purposes, the facilitator has at his/her disposal a number of extra resources, most of which are posted in a special section of the forum. These include media stories, background reading (articles, reports, etc.), but may also entail the introduction (by the facilitator) of visions or socio-technical imaginaries central to EU policy.

Issues and scenarios should be embraced, rejected or generated by participants themselves as much as possible. The role of the facilitator is similar to well established focusgroup facilitation. The films are aimed at creating initial responses from the participants and to get the forum started with the help of facilitation. The second phase draws on preliminary analysis of the first phase, in which possible converging points or points of disagreement are singled out. It will then introduce the formal ordering and representation tool, the KerBabel Deliberation Matrix, in order to carry out voting. In a next step, participants will be asked by the facilitator to explain/narrate/exemplify the formal vote. Initial responses will then be analyzed, and repeated/much commented issues will be used to generate specific lines of discussion aiming to produce scenarios. Hopefully, this second phase will also open up for more principled articulation and discussion, since large parts of the agenda should have been defined by the participants themselves. Thereafter, the discussion is closed and the deliberative materials subjected to both sociological and ethical analysis, hopefully contributing to the generation of a "databank of stories and narratives" in relation to each technology domain and its real-life implications.

\section{Concluding remarks}

We cannot come to final conclusions about TECHNOLIFE's successes and failures, from an exposition of the project while it is still being implemented. Nevertheless, in this last section we shall outline the criteria by which we think its successes and failures may be assessed. We will now sum up the main points of the paper and then we shall turn to some of the central presuppositions of the project which, we believe, provide key criteria for evaluating TECHNOLIFE outcomes. 
We started out by situating TECHNOLIFE within the wider context of European framework programs, especially the FP7 in which it takes part. A central (and critical) point concerns the ways in which predominant imaginaries of socio-technical futures for Europeans are articulated and projected by politicians and policy makers, scientists and engineers. Given the problematic character of many such visions in recent years, we pointed to corresponding problems for social cohesion and wider participation, and to the need for opening up and democratizing our socio-technical futures. Thereafter, the article described some of the ("mediating") institutions that have emerged on the interfaces between science, technology and society, in order to deal with the tensions associated with expert privilege, public participation and ways of governing. We pointed out a number of shortcomings, simultaneously institutional, epistemological and regulatory, placing the effectiveness and long-term legitimacy of mediating institutions under scrutiny.

The concrete proposals put forward by the TECHNOLIFE consortium, center on a number of concepts, aimed to shift the epistemological and institutional emphasis, and the corresponding practices. The brief descriptions we gave of our scoping/mapping exercises indicate how the problems of institutionalization and narrow participation may be seen to play out within three technological domains. Following our discussion of relevant domain-specific issues and imaginaries, we outlined our selection of participants, and explained what we see as four main groups or participant categories. The selection process, in particular, allowed us more thorough reflection on the significance of the concepts, imagined communities, and (socio-technical) imaginaries, which are central to the project. Also, whereas conventional notions of community are taken into account, we point out the critical importance of seeing publics as self-organizing and assembling around issues of concern as well as the emerging imaginaries of socio-technical development. The normative implications of these distinctions remain to be spelled out in further sociological and ethical interpretations and validations, following the deliberative phase of the project.

Turning to the criteria for assessing the project, one distinction will be important to keep in mind: TECHNOLIFE is both conceptual and empirical. Firstly, we seek to develop new concepts for use in ethics and technology assessment. Empirically, we aim to provide new insights into how groups and individuals imagine new technologies and their wider ethical and social implications. Ideally, the conceptual and empirical goals should come together in the execution of the project. However, it is also possible that the project fails on account of one, while succeeding with the other. Secondly, the TECHNOLIFE consortium is developing a methodology experimentally, so its success can hardly come to hinge upon expectations 
about completeness in terms of overview of the socio-technical domains in question (the empirical part mentioned above must also be seen in this light). The project would be validated first and foremost according to its capacity to generate method(s) that can be used, reproduced and developed further by others.

This being said, the project should, in one form or other, contribute to the ways in which the problems, described in sections 2 and 3, are dealt with. What is central here is the "framing problem", described in section 3, so another mark of success or failure will be the capacity of the project to generate responses that go beyond the ways in which ordinary ethics, public consultations or technology assessments communicate with groups and individuals. Is the project capable of generating interesting, meaningful and unexpected insights into the three technology domains? In order to answer that question, key points of reference will be existing ethical approaches to the respective domains. Section 4, on the scoping exercises, situates the project in relation to certain (broad) challenges already identified as ethically contentious. But our point of departure is to challenge the ways in which issues are commonly framed in public engagements and technology assessments (outlined in section 3), as well as in rethinking criteria for selecting participants (outlined in section 5). A mark of success or failure will be the broadness of responses. Is the methodology, proposed and tested in this project, able to generate meaningful, relevant and interesting responses from participants, while casting light on ethically contentious issues, not only from a number of viewpoints, but also unique viewpoints?

Finally, how will the conceptual apparatus be assessed? Does it provide us with meaningful ways of analyzing the material gathered, and is it capable of generating insights that can be generalized and used both descriptively and normatively? Are the central concepts, (socio-technical) imaginaries and imagined communities, helpful, given the ambiguity of their status as both social scientific categories and normative concepts? An important goal of the project is to achieve capacity to bridge gaps between disciplines such as STS, ethics, environmental governance and political theory, and in ways that directly relate to issues of ethics and regulation of the technology domains in question. For the purpose of achieving that goal, we apply the central concepts. The TECHNOLIFE consortium argues that large-scale technological developments are in need of integrated insights from fields such as those we mention here, in order to create "new ethical frameworks" that take into account imaginaries and dynamic community formations.

The motivation for writing this paper is to share our ambition to produce a generic methodological design that can be used by others - researchers, policy-makers, NGOs and 
citizens alike - who wish to detect, understand and mediate concerns. Such concerns need of course not be restricted to issues of technological development. An important element of the project is therefore an open access policy, aiming for modes of participatory research, also, after the TECHNOLIFE project is completed. Conversely, we encourage interested readers to contact us.

\section{Bibliography}

Aarts, E. and Grotenhuis, F. (2009). Ambient Intelligence 2.0: Towards Synergetic Prosperity. In M. Tscheligi, B. de Ruyter, P. Markopoulus, R. Wichert, and T. Mirlacher (eds) Proceedings of the Third European Conference on Ambient Intelligence, Salzburg, Austria, Nov. 18-21 2009. Volume 5859 of Lecture Notes in Computer Science. Springer Verlag, pp. 1-13.

Aarts, E. and Encarnação, J. (2008). Into Ambient Intelligence. In E.H.L. Aarts and J.L. Encarnação (eds) True Visions: The Emergence of Ambient Intelligence. Springer Verlag, pp. 1-17.

Anderson, B. (2006 [1983]). Imagined Communities, London, New York: Verso.

Beck, U. (1992). Risk Society. Sage Publications.

Beck, U. and Bonss, W. (eds) (2001). Die Modernisierung der Moderne. Frankfurt am Main: Suhrkamp Verlag.

Beck, U. (2006) Cosmopolitan Vision (Cambridge: Polity Press).

Bibel, W (ed) (2004). Converging Technologies and the Natural, Social and Cultural World. Special Interest Group Report for the European Commission via an Expert Group on Foresighting the New Technology Wave. European Communities, 07/2004.

Bigo, D. (2006). Liberty, Whose Liberty? The Hague Programme and the Conception of Freedom. In T.B.A.S. Carrera (ed) Security Versus Freedom? A Challenge for Europe's Future. Burlington: Ashgate.

Brekke, O. A. and Simes, T. (2006). Population Biobanks: The Ethical Gravity of Informed Consent. BioSocieties 1(4). pp. 385-98.

Bostrom, N. (2005). In defense of posthuman dignity. Bioethics 19(3): 202-214.

Council of the European Union. (2009). The Stockholm Programme - An open and secure Europe serving and protecting the citizens. EU Presidency to General Affairs Council/European Council (Brussels 2.12.2009). Available online at: http://www.se2009.eu/polopoly_fs/1.26419! menu/standard/file/Klar_Stockholmsprogram.pdf

Council of the European Union. (2004). The Hague Programme : strengthening freedom, security and justice in the European Union. EU General Secretariat to Delegations (Brussels 13.12.2004). Available online at: http://ec.europa.eu/justice_home/doc_centre/doc/hague_programme_en.pdf

Dewey, J. (1927). The Public and its Problems. An Essay in Political Inquiry. New York: Henry Holt and Co.

European Commission (2001). European Governance: A White Paper (Brussels, 25.7.2001). COM $2001 / 428$. 
European Commission. (2004). Area of Freedom, Security and Justice: Assessment of the Tampere programme and future orientations. Commission of the European Communities to the Council and the European Parliament (Brussels, 2.6.2004). Available online at: http://ec.europa.eu/justice_home/doc_centre/intro/docs/bilan_tampere_en.pdf

European Commission (2008). New tools for an integrated European Border Management Strategy. MEMO/08/85 Brussels, 13 February 2008.

European Commission. (2009a). FET Research Roadmaps: Pointing the Way to Future ICTs. Future and Emerging Technologies, Proactive. European Communities, 03/2009.

European Commission. (2009b). Moving the ICT frontiers - a strategy for research on future and emerging technologies in Europe. Communication from the Commission to the European Parliament, the Council, the European Economic and Social Committee and the Committee of the Regions (Brussels, 20.4.2009), COM 2009/184.

European Commission. (2010). Europe 2020: a strategy for smart, sustainable and inclusive growth. Communication of the European Commission. Available at http://ec.europa.eu/eu2020/pdf/COMPLET\%20EN\%20BARROSO\%20\%20\%20007\%20\%20Europe\%202020\%20-\%20EN\%20version.pdf

European Parliament. (1999). Tampere European Council, 15 and 16 October 1999 : Presidency Conclusions. Council of the European Union. Available online at: http://www.europarl.europa.eu/summits/tam_en.htm

Expert Group on Science and Governance. (2007). Taking European Knowledge Society Seriously. Directore-General for Research, European Commission.

Fleischer, T., Decker, M. and Fiedeler, U. (2005). Assessing emerging technologies-Methocological challenges and the case of nanotechnology. Technological Forecasting \& Social Change 72: $1112-1121$.

Gadal, S. (2008). Métropolisations et risques : enjeux politiques, humains et sociétaux. Géographes et assureurs face aux risques naturels. Niort: Editions MAIF.

Gibbons, M. (1999). Science's new Social Contract with Society. Nature 402: 11-18.

Gibson, W. (1984). Neuromancer. New York: Penguin.

Green, J. (2007). Democratizing the future: Towards a new era of creativity and growth. Koninklijke Philips Electronics N.V.

Hayes, B. (2006). NeoConOpticon. The EU Security-Industrial Complex. The Transanational Institute/Statewatch, Amsterdam.

Hayles, K. (1999). How We Became Posthuman: Virtual Bodies in Cybernetics, Literature, and Informatics. University of Chicago Press.

Heidegger, M. (1977). The Question Concerning Technology. In M. Heidegger, The Question Concerning Technology and Other Essays (translated w/introduction by W. Lovitt). New York: Harper \& Row, pp. 3-35.

Holm, S. (2007). Naturalness and Anthropology in Modern Bioethics, with a Special View to Transand Post-Humanism. In H. Kragh (ed.) Theology and Science -Issues for Future Dialogue. Aarhus: University of Aarhus.

Irwin, A. (2006). The Politics of Talk: Coming to Terms with the 'New' Scientific Governance. Social Studies of Science 36(2). pp. 299-320. 
This is Kristrún's draft copy, freely available for fair use (see http://en.wikipedia.org/wiki/Fair_use) !

Irwin, A., and Wynne, B. (1996). Misunderstanding Science? The Public Reconstruction of Science and Technology. Cambridge, Cambridge University Press.

ISTAG (2001). ISTAG Scenarios for Ambient Intelligence in 2010. Report EU Commission (Final Report). Available at http://cordis.europa.eu/ist/istag-reports.htm

Jasanoff, S. (2003). Technologies of Humility: Citizen Participation in Governing Science. Minerva 41: 223-244.

Jasanoff, S. (2005). Designs on Nature. Science and Democracy in Europe and the United States. Princeton, Princeton University Press.

Joint Research Center (2005). Biometrics at the Frontiers: Assessing the Impact on Society. In European Commission, Institute for Prospective Technology Studies.

Latour, B. (1993) We Have Never Been Modern. New York: Harvester Wheatsheaf.

Latour, B. (2005) Reassembling the Social. An Introduction to Actor-Network-Theory. Oxford: Oxford University Press.

Marres, N. ( 2005). Issues Spark a Public into Being: A Key but Often Forgotten Point of the Lippmann-Dewey Debate. In B. Latour and P. Weibel (eds) Making Things Public: Atmospheres of Democracy. MIT Press.

National Research Council. (2007). Putting people on the map: protecting confidentiality with linked social-spatial data. Panel of confidentiality issues arising from the integration of remotely sensed and self-identifying data. In M.P. Gutmann and P.C. Stern (eds) Committee on the Human Dimensions of Global Change: Division of Behavioral and Social Sciences and Education. Washington, DC: The National Academies Press.

Nowotny, H., Scott, P. and Gibbons, M. (2001). Re-Thinking Science. Knowledge and the Public in an Age of Uncertainty. Cambridge: Polity Press.

O'Connor, M., Bureau, P. and Reichel, V. (2007). Deliberative Sustainability Assessment with the Online kerDST Deliberation Support Tool. Cahier 07-03, C3ED. Université de Versailles, Guyancourt.

O'Neill, O. (2002) A Question of Trust (Cambridge: Cambridge University Press).

Rocco, M. C. and Bainbridge, W. S. (2002). Converging Technologies for Improving Human Performance: Nanotechnology, Biotechnology, Information Technology and Cognitive Science. Arlington, Virginia: NSF/DOC-sponsored report.

Rommetveit, K. (2008). Bioethics, biopower and the post-genomic challenge. In S. Holm (ed) Ethics, Law and Society. Aldershot: Ashgate.

Rose, N. (2007). The Politics of Life Itself. Biomedicine, Power, and Subjectivity in the Twenty-First Century. Princeton University Press.

Strathern, M. (ed) (2000). Audit cultures: anthropological studies in accountability, ethics, and the academy. London and New York: Routledge.

Sutrop, M. (Forthcoming). Ethical Issues in Governing Biometric Technologies.

Taylor, C. (1985). What is Human Agency? In, Philosophical Papers. Cambridge University Press.

Wright, D., Gutwirth, S., Friedewald, M., et al. (2008). Safeguards in a World of Ambient Intelligence. The International Library of Ethics, Law and Technology, vol.1. Springer Verlag. 